\title{
A IMPORTÂNCIA DA PECUÁRIA PARA O DESENVOLVIMENTO REGIONAL NO ESTADO DO RIO GRANDE DO NORTE: Uma Análise de Matriz Insumo-Produto
}

http://dx.doi.org/10.21527/2237-6453.2021.56.11241

Recebido em: 6/11/2020

Aceito em: 13/5/2021

\author{
Maria Kaliane Freitas Mota ${ }^{1}$, João Maria Filgueira², Maíra Melo de França², \\ Renato Samuel Barbosa de Araújo²
}

\section{RESUMO}

A presente pesquisa objetiva analisar a relevância da pecuária para o desenvolvimento regional do Estado do Rio Grande do Norte (RN) como forma de reduzir as desigualdades sociais e regionais. Utiliza da metodologia exploratório-descritiva a partir da análise da matriz insumo-produto, desenvolvida por Guilhoto et al. (2010). Analisa os impactos da pecuária para a economia, sociedade e governo, com ênfase na geração de emprego, massa salarial e produção. Constata a importância estratégica apresentada pela pecuária para fomentar o desenvolvimento socioeconômico. Conclui que a criação de bovinos é relevante para o desenvolvimento regional, principalmente para a geração de emprego direto e produção, destacando-se as atividades de produção do leite e seus derivados. Sugere ao Estado a instituição de políticas públicas para o fortalecimento de atividades de competência local, distribuindo os resultados econômicos para a sociedade.

Palavras-chave: insumo-produto; desenvolvimento regional; pecuária; Estado do Rio Grande do Norte.

\section{THE IMPORTANCE OF LIVESTOCK FOR REGIONAL DEVELOPMENT IN RIO GRANDE DO NORTE STATE: AN ANALYSIS OF MATERIAL INPUT-OUTPUT}

\section{ABSTRACT}

This research aims to analyze the relevance of livestock for the regional development of the State of Rio Grande do Norte (RN) as a way to reduce social and regional inequalities. Uses the exploratory-descriptive methodology from the analysis of the input-product matrix, developed by Guilhoto et al. (2010). It analyzes livestock impacts for the economy, society and government, with an emphasis on job creation, salary and production generation. Verifies the strategic importance presented by livestock to foster socioeconomic development. Concludes that cattle breeding is relevant to regional development, mainly for the generation of direct employment and for the generation of production, standing out the activities of milk production and its derivatives. It suggests to the State the implementation of public policies to strengthen activities of local competence, distributing the economic results to society.

Keywords: input-product; regional development; livestock; Rio Grande do Norte State.

\footnotetext{
${ }^{1}$ Autora correspondente. Instituto Federal do Rio Grande do Norte (IFRN). Natal/RN, Brasil. Avenida Senador Salgado Filho, 1559, Tirol. Natal/RN, Brasil. CEP 59015-000. http://lattes.cnpq.br/6126378798850244. https://orcid.org/0000-0002-4683-8891. kalianefreitas@hotmail.com

${ }^{2}$ Instituto Federal do Rio Grande do Norte (IFRN). Natal/RN, Brasil.
} 


\section{INTRODUÇÃO}

A crescente competitividade dos mercados nacional e internacional vem ressaltando a importância do desenvolvimento regional com o intuito de alcançar a equidade socioeconômica. Para tal, é importante que sejam identificados os setores-chave que dinamizam a economia com aquisições e ofertas de insumos do sistema produtivo (HENRIQUE et al., 2019). $\mathrm{Na}$ atualidade brasileira, para a redução das desigualdades regionais, são necessários estudos que identifiquem possíveis cadeias com o potencial de constituir a opção de diversificação produtiva à região e que analisem essas atividades de forma a identificar suas potencialidades e possíveis fragilidades com o objetivo de contribuir para o desenvolvimento territorial, conforme defendido por Griebeler et al. (2019).

Filgueira et al. (2020) apresentam a discussão sobre o desenvolvimento socioeconômico, o qual é concretizado a partir do fortalecimento de atividades de competência local, de forma que, quando se identificam suas especialidades, se direcionam esforços objetivando reforçar seus resultados econômicos e a distribuição social dos mesmos.

O espaço geográfico do Brasil é marcado pela monocultura e pela constituição de grandes propriedades de terra como consequência da modernização agrícola, que aconteceu via modelos exógenos de crescimento econômico (DIAS et al., 2013). Esse cenário é retratado no Estado do Rio Grande do Norte, que tem histórico de formação de grandes latifúndios e diferentes níveis de desigualdades econômicas e sociais que abrangem o enfrentamento de condições climáticas desfavoráveis, como é o exemplo das secas e a discrepância da distribuição de renda, dentre outros.

É importante destacar que constituem objetivos fundamentais do Brasil, entre outros, a garantia do desenvolvimento nacional e a redução das desigualdades sociais e regionais, conforme assegurado nos incisos II e III do artigo 3ํ da Constituição Federal de 1988 (BRASIL, 1988).

Neste contexto, o trabalho tem como objetivo contribuir para a análise socioeconômica do Estado do Rio Grande do Norte (RN) a partir do estudo da matriz insumo-produto, com enfoque direcionado à pecuária e com a finalidade de subsidiar a formulação de políticas públicas que possam contribuir para a melhoria do bem-estar da sociedade.

Sob o parâmetro da matriz insumo-produto, analisada nessa construção, utilizou-se a matriz insumo-produto elaborada pelo portal Nereus (2020) e por Guilhoto et al. (2010) para o Estado do Rio Grande do Norte. Essa análise setorial estima a capacidade que cada segmento possui para gerar efeitos locais e regionais.

A metodologia insumo-produto permite uma visão detalhada do sistema econômico, que pode ser estudado em duas ou mais regiões e estima seu fluxo de bens e serviços. Dessa forma, é possível realizar análises de produção, massa salarial, geração de tributos, emprego e renda, entre outras.

São abordados os resultados da pecuária, com foco no segmento da criação de bovinos, e analisados fatores que podem estar relacionados aos seus respectivos desempenhos. Ressalta-se que a pecuária, objeto de diversos estudos, faz-se de grande relevância para o desenvolvimento de uma localidade e para a melhoria social e econômica das pessoas, inclusive para a economia familiar, conforme asseguram Eurich, Weirich Neto e Rocha (2016). Ademais, é importante destacar que o desenvolvimento regional, que este estudo preconiza para o Rio Gran- 
de do Norte, engloba expansão do trabalho, da renda e do capital, fortalecida e sustentada com a participação de gestores públicos, pesquisadores e lideranças representativas locais, que poderão utilizar subsídios oriundos da análise aqui apresentada (CARDOSO; OLIVEIRA; SILVA, 2013; SILVEIRA et al., 2020).

O Rio Grande do Norte possui condições climáticas favoráveis à criação de gado, marcadas pelo calor, pela luminosidade e pela umidade adequada, além de apresentar disponibilidade de grandes extensões territoriais com custo consideravelmente baixo (FAERN, 2018).

Outro fator relevante a ser considerado é o da geração de diversos produtos, obtidos a partir da criação bovina. O leite de vaca apresenta-se com relevância para o consumo local, sendo comercializado in natura ou pasteurizado e, também, utilizado para fabricação de produtos derivados, a exemplo do queijo, da coalhada, da manteiga da terra e do iogurte, além da própria comercialização da carne, que é rica em nutrientes e bem-aceita na alimentação do Estado.

Na sequência desta Introdução será apresentado o referencial teórico sobre Matriz Insumo-Produto e Desenvolvimento Regional e Pecuária, seguido pela apresentação da Metodologia. Logo após, serão discutidos os Resultados por meio de uma análise dos impactos do setor da pecuária como fator relevante para desencadear o desenvolvimento socioeconômico no Rio Grande do Norte, a partir de um estudo da matriz insumo-produto sobre esse Estado. Por último, são apresentadas as Considerações Finais e as Referências Bibliográficas consultadas.

\section{MATRIZ INSUMO-PRODUTO}

A Teoria de Insumo-Produto apresenta-se como uma técnica presente no estudo de relações regionais, revelando a interdependência dentre os setores da economia. Conforme Leontief (1983), a matriz insumo-produto demonstra a produção de cada setor da atividade econômica e detalha a respectiva demanda e o consumo intermediário, representando o circuito econômico.

Sobre a relação dos fatores de produção, Cano (1998, p. 52) elenca que as quantidades de "fatores", o tipo e a quantidade de matérias-primas podem variar para a utilização na produção de um determinado bem ou serviço, desde que para a produção do bem em questão existam alternativas técnicas de produção.

A significância da metodologia de estudo de matriz para o desenvolvimento é utilizada para diferentes localidades, sendo de aplicação internacional. A partir desta metodologia, por exemplo, Sanén e Gamboa (2016) propuseram incremento no estudo do método, aplicando a construção e a análise das matrizes regionais de insumo-produto para o Estado de Sonora no México, a partir de uma nova abordagem de baixo para cima, o que revelou, segundo os autores, novas propostas de pesquisa para estudos aplicados ao desenvolvimento de análises econômicas espaciais e pesquisas experimentais de estudos econômicos regionais e urbanos.

Dando continuidade ao estudo e aplicabilidade do modelo insumo-produto, Firme (2017) propôs a construção de uma matriz inter-regional de insumo-produto contendo os fluxos comerciais entre as regiões de Minas Gerais (MG), Restante do Brasil (RB) e Resto do Mundo (RM). Ao final, Firme (2017) constatou que, analisando os multiplicadores de produção, para o caso de Minas Gerais, o setor de extrativo mineral apresenta o maior coeficiente multiplicador da região $(2,57)$, revelando que a cada $R \$ 1,00$ investido neste setor, localizado em $M G$, haverá um 
acréscimo de $R \$ 1,57$ na produção total (que poderá permanecer em MG ou transbordar para o RB e RM).

Desse modo, em virtude da consistência do modelo insumo-produto, comprova-se a relevância que ele oferece para estudos de atividades econômicas e para o planejamento de políticas públicas, inclusive com visualização dos efeitos que ocorrerão na região produtora e nas demais regiões. Estudos dessa natureza mostram-se essenciais para o desenvolvimento econômico e social como perspectiva para a redução das desigualdades socioeconômicas.

Destaca-se, também, o estudo de Henrique et al. (2019) sobre as interligações setoriais na estrutura produtiva do Paraná, com o objetivo de conhecer o impacto de cada setor dentro da economia, identificando os principais setores motrizes que estimulam a economia em termos de compra e ofertas de insumos do sistema produtivo, sendo eles: os da construção, comércio, refino de petróleo, transporte terrestre e outros produtos alimentares.

\section{DESENVOLVIMENTO REGIONAL E PECUÁRIA}

O surgimento do estudo sobre desenvolvimento regional no mundo, praticamente, só começou a acontecer no período da Segunda Guerra Mundial, quando países enfrentaram crises econômicas, e os problemas das desigualdades regionais ficaram em evidência (DINIZ, 2009). Em decorrência disso, passou-se à construção do campo teórico, dando origem a duas Escolas de pensamento. Uma delas, na Alemanha, constituiu a Ciência Regional, sob a liderança de Walter Isard (1951), que trabalhou com a noção de modelos de equilíbrio, com ênfase no papel dos custos de transporte em mercados concorrenciais, desenvolvendo, paralelamente, um conjunto de técnicas de análise regional, entre as quais os modelos de insumo-produto.

A outra escola foi desenvolvida na França, sob liderança de François Perroux (1967), na qual foi criado o conceito de polo de crescimento e do papel central da empresa motriz para o crescimento desses polos.

No Brasil, o estudo do desenvolvimento regional se deu com ênfase ao trabalho de Furtado (1964), que, inicialmente, tinha uma posição mais voltada ao combate às secas no Nordeste como requisito para seu desenvolvimento. Posteriormente, percebeu-se que as raízes da desigualdade regional são mais estruturais e requerem distribuição de renda, desenvolvimento industrial e tecnológico.

Nesse sentido, Furtado (1967) concluiu que a desigualdade está ligada à forma como se introduzem e se distribuem as modernas tecnologias, e enfatizou a importância de uma abordagem interdisciplinar para uma teoria da estrutura espacial, com ênfase nos estudos sobre os processos de urbanização, dos custos de comutação, das migrações.

No contexto da abordagem interdisciplinar, a partir de 1990 as aceleradas mudanças tecnológicas e a emergência de novos centros produtores, baseados em tecnologias avançadas, abriram a corrida para a busca da inovação como mecanismo de desenvolvimento regional (DINIZ; GONÇALVES, 2005; DINIZ; SANTOS; CROCCO, 2006).

Várias pesquisas têm sido realizadas no contexto do desenvolvimento regional, e seus resultados permitem destacar a importância do envolvimento da sociedade, governo e setor produtivo, no sentido de que o desenvolvimento socioeconômico seja produzido e distribuído 
para todos os agentes envolvidos. Em particular, pode-se destacar que esse desenvolvimento deve ocorrer a partir de potencialidades locais.

De fato, promover o desenvolvimento a partir das potencialidades locais, conforme esclarecem Griebeler et al. (2019), é uma estratégia muito importante para o fortalecimento socioeconômico. Decorrente desse fato, Silveira et al. (2020) destacam ainda que a dinâmica do emprego na região revela tanto o significado social e econômico que ele tem para a reprodução social dos trabalhadores, quanto para o processo de reprodução do capital das empresas instaladas nos municípios da região.

Na perspectiva do desenvolvimento regional baseado na agropecuária, Coutinho et al. (2019), em seu estudo sobre geração de emprego nos municípios de Mato Grosso do Sul, constataram que as atividades de base agropecuária têm gerado emprego, colaborando no aquecimento econômico dos municípios, além de serem geradoras de insumos para outros setores, constituindo-se peça-chave na engrenagem da construção do crescimento e do desenvolvimento regional.

No caso específico do Rio Grande do Norte, a pecuária representa uma dessas potencialidades relevantes para desencadear o desenvolvimento regional, o que permite compreender a sua importância neste estudo.

Em relação ao fortalecimento na realidade local, apesar de dificuldades no acesso à água e de escassez de alimentos para os animais durante o período de seca, a pecuária, no Rio Grande do Norte, é uma atividade que se desenvolve dentro de um contexto produtivo dinâmico, seja do ponto de vista do rebanho, do abate ou do leite (COSTA, 2017; FAERN, 2018). Dela participam diversas famílias na maioria dos municípios do Estado, tanto no âmbito familiar quanto no empresarial.

Como foi possível mostrar, o desenvolvimento regional precisa considerar os elementos fundamentais que caracterizam a sociedade, a economia, o governo e a política, de tal forma que este desenvolvimento fortaleça, ainda mais, tais elementos (FILGUEIRA et al., 2020). Nesse sentido, a pecuária nos municípios do Rio Grande do Norte está entre esses elementos fundamentais, representando um elo que fortalece e dinamiza os municípios e os polos regionais das mesorregiões desse Estado, sendo o objeto escolhido por esta pesquisa para analisar o desenvolvimento regional.

\section{METODOLOGIA}

A metodologia empregada quanto aos objetivos foi do tipo exploratório-descritiva, utilizando-se de dados secundários da matriz insumo-produto para o Rio Grande do Norte, de investigações bibliográficas e de pesquisas que envolvem o meio eletrônico.

Optou-se pela pesquisa exploratória por esta permitir a melhor identificação do objeto estudado e por seguir os princípios de Marconi e Lakatos (2003), os quais mostram que este tipo de investigação desenvolve um aumento da familiaridade do pesquisador com o tema, e possibilita o desenvolvimento de hipóteses e o esclarecimento de conceitos. Ainda, conforme Marconi e Lakatos (2003), o caráter descritivo advém da exposição concisa dos fatos e fenômenos pesquisados, caracterizando o fenômeno estudado, descrevendo suas características, suas variáveis e explorando as relações entre ambas. 
Em países de dimensões continentais, como o Brasil, os estudos regionalizados são ainda mais importantes para reduzir as desigualdades regionais. Em particular, esta pesquisa preenche uma lacuna nas pesquisas sobre o Rio Grande do Norte ao realizar uma análise estrutural da economia (MOTA; BARBOSA; FILGUEIRA, 2015).

Nesse sentido, para a efetivação dessa análise foram utilizadas as seguintes técnicas: a Matriz de Insumo-Produto e a identificação dos principais setores-chave para a geração de emprego, renda e produção. Com os resultados obtidos da integração das duas técnicas, pode-se subsidiar a formulação de estratégias para impulsionar o desenvolvimento socioeconômico.

$O$ universo desta pesquisa envolveu a análise de dados a partir da matriz insumo-produto divulgada, no ano de 2010, pelo Banco do Nordeste (BNB), por meio de um trabalho técnico da autoria de Guilhoto et al. (2010), intitulado de "Matriz de insumo-produto do Nordeste e Estados". Também se pautou nas análises realizadas por Mota (2012) a respeito da citada produção técnica.

A formação dos dados da matriz insumo-produto, elaborada por Guilhoto et al. (2010), segue os ditames do modelo de Leontief (1953), que descreve os fluxos intersetoriais de uma economia a partir de um sistema de equações simultâneas representado por:

$$
X=A X+Y
$$

No qual:

$X$ - vetor $(n \times 1)$ com os valores da produção total por setores;

$Y$ - é um vetor $(n \times 1)$ com os valores da demanda final setorial;

$A$-é uma matriz ( $n \times n)$ com os coeficientes técnicos de produção.

De acordo com este modelo, o vetor produção total é determinado unicamente pelo vetor de demanda final, ou seja, só há produção se houver demanda. Sendo assim, o vetor demanda é tratado como exógeno ao sistema:

$$
\begin{aligned}
& X=B Y \\
& B=(I-A)^{-1}
\end{aligned}
$$

De acordo com Guilhoto et al. (2010), B é uma matriz contendo a matriz inversa de Leontief e deve ser interpretada como sendo a produção total do setor "I" determinado, que é necessária para produzir uma unidade de demanda final do setor J relacionado.

Nesse caso, se houver um aumento da demanda por produtos de determinado setor $\mathrm{J} O$ impacto inicial corresponderá ao aumento da produção deste setor. Esta variação está refletida no primeiro termo "I" do somatório. Para aumentar a produção, porém, o setor "J" demandaria insumos também dos demais setores.

O modelo de insumo-produto Inter-regional, considerando as dimensões brasileiras, foi construído, de acordo com Guilhoto et al. (2010), compatibilizando a pauta de atividades e produtos da Matriz de Insumo-Produto (MIP) do Brasil e da Tabela de Classificação Nacional de Atividades Econômicas (CNAE). Por essa metodologia, utilizando-se o modelo de Leontief, torna-se viável a análise do impacto que diferentes estratégias setoriais possuem sobre a produção total, sobre o volume de importações e sobre a massa de rendimentos.

Neste estudo serão comentados, a partir de dados da matriz insumo-produto construída por Guilhoto et al. (2010), os resultados dos segmentos mais expressivos e de menores desempenhos e o setor de pecuária, a partir do segmento de bovinos, do Rio Grande do Norte, assim como serão avaliados os fatores que podem estar relacionados a seus respectivos desempenhos. 


\section{RESULTADOS}

A pesquisa faz uma análise do impacto da atividade pecuária no desenvolvimento regional do Rio Grande do Norte. Para isto, está estruturada nas seguintes partes: geração de emprego, geração de renda, analisada a partir da massa salarial, e geração de produção. A geração de emprego e renda compreende o aumento da atividade econômica por meio da criação ou expansão de unidades produtivas já existentes. A massa salarial está relacionada diretamente com a geração de produção, uma vez que o aumento da massa salarial impulsiona o consumo dos trabalhadores, resultando em um impacto positivo na economia.

\section{Geração de emprego direto, indireto e induzido}

De acordo com Guilhoto et al. (2010), a apreciação dos resultados, obtidos por meio do cálculo dos coeficientes de geração de emprego, baseia-se no cálculo dos coeficientes direto, indireto e induzido, que relaciona a quantidade de empregos aos valores monetários expressos em reais. Para compreensão deste indicador, deve-se considerar que a geração de emprego direto estipula a quantidade de empregos que são gerados em um determinado setor produtivo, quando a produção do mesmo setor é estimulada. $O$ indicador de emprego indireto estima quantos empregos são gerados em todos os outros setores, quando a produção de um determinado segmento é aumentada. O gerador de emprego induzido determina quantos empregos são criados em decorrência do aumento do consumo das famílias, influenciado pelo crescimento da renda da população, dado o aumento da quantidade de emprego direto e indireto.

Por esse método, conforme apresentado na Tabela 1, a criação de bovinos, no Rio Grande do Norte, obtém a geração de 157 empregos diretos no próprio setor, para cada inserção de um milhão nesta demanda. Em contrapartida, são gerados 19 empregos indiretos em outros setores produtivos e 103 empregos induzidos pelo aumento da renda e do consumo da classe trabaIhadora e, também, pelo desenvolvimento de atividades que decorrem da criação de gado. Isto gerou o total de 280 novos postos de trabalho em toda a economia nacional, pois os efeitos indiretos e induzidos consideraram, ainda, outras regiões, além do Nordeste. Destes, $78 \%$ dos empregos são gerados no RN, 8\% em outros Estados da região Nordeste e 14\% no restante do Brasil.

Tabela 1 - Efeito direto, indireto e induzido na geração de empregos no Rio Grande do Norte

\begin{tabular}{|c|c|c|c|c|c|c|c|c|}
\hline \multirow{2}{*}{ Setor } & \multicolumn{4}{|c|}{ Composiçaio do efeito } & \multicolumn{4}{|c|}{ Composição Regional } \\
\hline & Direto & Indireto & Induzido & Total & $\mathrm{RN}$ & $\mathrm{NE}$ & RBR & \\
\hline 1-Cana-de-açúcar & 667 & 11 & 106 & 784 & $93 \%$ & $3 \%$ & $4 \%$ & \\
\hline 2 - Extrativismo animal (pesca) & 625 & 33 & 98 & 756 & $91 \%$ & $3 \%$ & $6 \%$ & \\
\hline 3 - Bovinos & 157 & 19 & 103 & 280 & $78 \%$ & $8 \%$ & $14 \%$ & \\
\hline 4-Fab. de interm $p /$ resinas $e$ fibras & 3 & 20 & 49 & 72 & $47 \%$ & $19 \%$ & $34 \%$ & \\
\hline \multirow[t]{2}{*}{ 5- Fab. de Petroquimicos Básicos } & 2 & 18 & 53 & 73 & $48 \%$ & $18 \%$ & $34 \%$ & \\
\hline & \multicolumn{4}{|c|}{$\begin{array}{l}\text { Efeito Direto } \\
=\text { Efeito Indireto } \\
\text { Efeito Induzido }\end{array}$} & \multicolumn{4}{|c|}{$\begin{array}{l}\text { - Composição Regional RN } \\
\text { Composição Regional NE } \\
\text { Composição Regional RBR }\end{array}$} \\
\hline
\end{tabular}

Deve-se levar em consideração, conforme Guilhoto et al. (2010), que a geração de empregos diretos está associada com as características intrínsecas de cada setor, mas a geração indire- 
ta e induzida depende do contexto amplo, no qual um setor pode sofrer a influência de todos os outros, estendendo, então, as análises para as demais atividades econômicas.

Observa-se que a criação de gado, no geral, em virtude de suas características, possibilita a geração direta de emprego, a exemplo do próprio ato de cuidar do rebanho, incluindo mão de obra para disponibilização de alimento e, também, para a extração do leite. O leite produzido no Rio Grande do Norte, como relatado anteriormente, possui destinação direta para a alimentação, para o Programa do Leite e para a produção de diferentes produtos derivados, como o queijo de coalho e o de manteiga, a coalhada e a manteiga da terra. Dessa forma, constatam-se os benefícios da diversificação produtiva no desenvolvimento de região, conforme preconizado por Griebeler et al. (2019).

Cabe destacar a existência do efeito induzido que o segmento prospecta, atendendo aos preceitos de Dias et al. (2013), segundo os quais quando há valorização dos produtos de pequenos agricultores contribui-se para o resgate da cultura local e para o incentivo para a produção orgânica e a diversidade na produção. Nota-se que se faz necessário, cada vez mais, o fomento, por parte dos gestores públicos, para a valorização dos produtos locais.

Relata-se que a atividade bovina possibilita a geração de empregos com a comercialização da carne, destinada tanto ao consumo doméstico quanto às exportações, conforme informações extraídas do Ministério da Economia (BRASIL, 2020).

Destaca-se, também, a relevância de outros segmentos, como o da cana-de-açúcar, principalmente para a geração de empregos diretos, conforme demonstrado na Tabela 1. Para cada aumento de 1 milhão inserido na demanda de cana-de-açúcar do Rio Grande do Norte, são gerados 667 empregos diretos no setor; 11 empregos indiretos em outros setores produtivos e 106 empregos induzidos pelo aumento da renda e do consumo da classe trabalhadora. Isto gerou o total de 784 novos postos de trabalho em toda a economia nacional, pois os efeitos indiretos e induzidos consideraram outras regiões além do Nordeste. Destes, 93\% dos empregos são gerados no RN, 3\% em outros Estados da Região Nordeste e 4\% no restante do Brasil.

O Extrativismo animal (pesca) apresenta igualmente uma das melhores desenvolturas para a geração de empregos totais. Para cada aumento de 1 milhão, inserido em demanda do extrativismo animal do Rio Grande do Norte, foram gerados 635 empregos diretos no setor, 33 empregos indiretos em outros setores produtivos e 98 empregos induzidos pelo aumento da renda e do consumo da classe trabalhadora. Ao total foram gerados 756 novos postos de trabaIho em toda a economia nacional, pois os efeitos indiretos e induzidos consideraram também outras regiões além do Nordeste. Destes, $91 \%$ dos empregos são gerados no RN, $3 \%$ em outros Estados da Região Nordeste e 6\% no restante do Brasil.

A fabricação de intermediários para resinas e fibras apresenta-se, nessa dimensão social, como a atividade de menor capacidade geradora de empregos, tendo em vista que para cada milhão demandado obtém-se um retorno total de 72 empregos gerados em toda a economia. Destes, apenas 2 empregos são iniciados com a execução desta atividade, 18 são criados com as atividades indiretas e $53 \mathrm{com}$ a indução de renda dos trabalhadores, que se propagam nos demais setores econômicos e permitem a demanda por mais esta quantidade de vagas.

De acordo com Moreira (2007), os setores que são grandes empregadores de mão de obra menos qualificada e possuem grande massa de trabalhadores com rendimento baixo, contribuem para a melhoria da distribuição de renda quando estimulados. É nesse sentido que se 
revelam os principais segmentos geradores de emprego na matriz insumo-produto do Rio Grande do Norte, quais sejam, a cana-de-açúcar e o extrativismo animal (pesca), além de bovinos, que são empregadores de mão de obra menos qualificada e que permitem o alcance à renda por parte dos trabalhadores.

\section{Análise dos coeficientes de geração de massa salarial}

O coeficiente da geração de massa salarial revela o quanto os salários serão influenciados, de forma direta, indireta ou induzida, quando aumentada a demanda, de um segmento, em torno de 1 milhão de reais. Esclarece-se que a massa salarial não corresponde ao valor integral das remunerações, uma vez que são formadas também pelas contribuições sociais efetivas (previdência privada e oficial) e fictícias e pelo montante dos salários.

O incremento de 1 milhão na criação bovina, no Rio Grande do Norte, corresponde diretamente a 190 mil de aumento direto da massa salarial do setor. Esta relação proporciona um efeito indireto em atividades afins no valor de 70 mil reais. A relação desse setor, de forma induzida, impulsiona outros segmentos da economia a amplia este aumento da massa salarial para 380 mil reais.

Tabela 2 - Geração de salários no Rio Grande do NorteFonte: Adaptada de Guilhoto et al. (2010).

\begin{tabular}{|c|c|c|c|c|c|c|c|c|}
\hline \multirow{2}{*}{ Setor } & \multicolumn{4}{|c|}{ Composiçâo do efeito } & \multicolumn{4}{|c|}{ Composição Regional } \\
\hline & Direto & Indireto & Induzido & Total & $\mathrm{RN}$ & $\mathrm{NE}$ & RBR & \\
\hline Educação Pública & 0,7 & 0,03 & 0,42 & 1,15 & $77 \%$ & $5 \%$ & $18 \%$ & \\
\hline Cana-de-açúcar & 0,55 & 0,05 & 0,39 & 0,99 & $73 \%$ & $6 \%$ & $21 \%$ & \\
\hline Bovinos & 0,19 & 0,07 & 0,38 & 0,65 & $55 \%$ & $10 \%$ & $36 \%$ & \\
\hline Serviços Imobiliários e Aluguel & 0,01 & 0,01 & 0,28 & 0,3 & $45 \%$ & $12 \%$ & $43 \%$ & \\
\hline \multirow[t]{2}{*}{ Refino de Petróleo e Coque } & 0,02 & 0,16 & 0,21 & 0,39 & $42 \%$ & $12 \%$ & $46 \%$ & \\
\hline & \multicolumn{4}{|c|}{$\begin{array}{l}\text { Efeito Direto } \\
\text { Efeito Indireto } \\
\text { Efeito Induzido }\end{array}$} & \multicolumn{4}{|c|}{$\begin{array}{l}\text { Composição Regional RN } \\
\text { Composição Regional NE } \\
\text { Composição Regional RBR }\end{array}$} \\
\hline
\end{tabular}

Fonte: Adaptada de Guilhoto et al. (2010).

De forma geral, são adicionados 650 mil reais à massa salarial ao ser injetado 1 milhão na criação de bovinos. Este acréscimo é distribuído de maneira que $55 \%$ do valor destina-se à remuneração dos assalariados do RN, $10 \%$ ao Nordeste e $36 \%$ designado aos demais Estados do Brasil.

De forma comparativa, observa-se que, em termo salarial, o melhor desempenho da criação bovina é na sua modalidade induzida em outros setores. Em contrapartida, os menores efeitos salariais diretos e indiretos revelam a precariedade do desenvolvimento das atividades primárias, muitas vezes marcadas pela baixa remuneração, informalidade de empregos e condições de trabalhos insalubres, com exposição a agentes nocivos à saúde, tais como poeira e frequente incidência de radiação solar no decorrer do dia.

Sob a perspectiva governamental, cita-se a contribuição do Programa Nacional de Fortalecimento da Agricultura Familiar (Pronaf), regulado pela Resolução no 3.599/2008 e pela Resolução no 4.339/2014, ao instituir o bônus de adimplência da Linha de Crédito do Pronaf, contribuindo com o financiamento das atividades agropecuárias e não agropecuárias desenvolvidas no estabelecimento rural ou em áreas comunitárias rurais próximas. Observa-se que este 
subsídio contribui para a fixação de renda dos produtores rurais, principalmente nos períodos de crises (BELTRAME; PEREIRA, 2017).

Ressalte-se que o Pronaf isoladamente não promove impactos à vida socioeconômica, conforme Beltrame e Pereira (2017). Ademais, é importante mencionar que a atividade pecuária bovina pode desencadear impactos negativos ao meio ambiente, além da existência de latifúndios, o que implica custo à redução das desigualdades regionais (FAERN, 2018).

O impacto das secas é alto para os criadores, uma vez que, em diversas localidades do interior do Estado, o pasto é insuficiente e, para evitar a morte dos animais, é necessária a compra de rações, que possui custo consideravelmente alto (FAERN, 2018; SOUZA; AQUINO, 2018); fator este que interfere na renda mensal dos pequenos criadores e, inclusive, é determinante para que eles não consigam aumentar a criação.

O percentual (36\%) de aumento salarial que acontece nos demais Estados do país demonstra a demanda desta atividade para outras regiões e, ao mesmo tempo, pode revelar que há insuficiente retenção da geração de salários para a localidade e Estados vizinhos da mesma região.

Retomando os resultados expressos na Tabela 2, no que diz respeito à geração de massa salarial para o Rio Grande do Norte, a educação pública destaca-se como a atividade que ocasiona maior retorno salarial. Seus efeitos são fortemente perceptíveis de forma direta, incrementando, diretamente, os salários em 700 mil na remuneração dos agentes envolvidos nessa atividade. Nas atividades indiretamente interligadas, os efeitos salariais são de 30 mil reais e, de maneira induzida, corresponde a 420 mil.

A representatividade da Educação Pública para a geração de salários, conforme Mota, Barbosa e Filgueira (2015), possui bastante aspectos positivos, uma vez que permite a contratação de maior número de profissionais e, consequentemente, traz benefícios para diversas pessoas, que são alcançadas diretamente com aprendizado e formação cidadã e, também, proporciona ganhos para outros setores econômicos, que são influenciados pela compra em virtude do aumento do poder aquisitivo dos agentes envolvidos na educação, permitindo-se concluir que o incremento salarial da educação proporciona bem-estar social e melhoria das condições de vida de diversas pessoas.

Conforme matriz apresentada na Tabela 2, os retornos salariais dão-se no percentual de $77 \%$ nas remunerações potiguares, $5 \%$ nos salários da população dos outros Estados do Nordeste e $18 \%$ nos outros Estados brasileiros.

De acordo com a Tabela 2, a cana-de-açúcar possui potencial significância para a obtenção de aumento da massa salarial dos envolvidos nessa atividade. Possui efeitos diretos de 0,55 milhões dos salários dos trabalhadores deste setor, induz ainda 0,39 milhões nos demais setores da economia e, de forma indireta, proporciona acréscimo de 0,05 milhões. A maior parte do incremento salarial (73\%) é para os habitantes do próprio RN, $6 \%$ para os vizinhos da Região Nordeste e $21 \%$ para o restante do país.

Já os serviços imobiliários e aluguel apresentam-se menos expressivos na geração de massa salarial do Estado do Rio Grande do Norte, com igual aumento direto e indireto de 0,01 milhão na atividade e 0,28 induzido nas demais atividades, totalizando, assim, 0,30 milhão de incremento total de remuneração dos salários. O setor do refino de petróleo e coque apresenta-se com pouca expressividade quando se investe um milhão, havendo correspondência direta 
de 20 mil de aumento direto da massa salarial do setor. A relação desse setor com outros da economia amplia este aumento da massa salarial para 390 mil ao considerar também os efeitos indiretos e induzidos. Desse rendimento $42 \%$ continuam no Estado, $12 \%$ vão para o restante do Nordeste e os demais (46\%) para os outros Estados do Brasil.

\section{Análise dos coeficientes de geração de produção}

A geração de produção setorial do Estado do Rio Grande do Norte possibilita a identificação dos setores que se destacam no que condiz ao efeito multiplicador da produção, e demonstra o potencial que cada segmento tem para gerar mais produção de forma indireta e induzida, mediante um impacto.

Os efeitos diretos, indiretos e induzidos quantificam o aumento do valor da produção, que é induzida pelo aumento da demanda final de cada setor específico para a região estudada. O efeito direto da produção é igual a 1 para qualquer setor, o indireto revela o quanto a produção em outros setores é aumentada em milhões de reais e o efeito induzido expressa os ganhos para todos os outros setores da economia.

Como pode ser observado na Tabela 3, a criação de gado no Estado do Rio Grande do Norte, quando demandada em um milhão, apresenta retorno indireto em outros setores na equivalência de 590 mil. Somando a influência direta e indireta, tem-se um crescimento induzido de 2,63 milhões em todos os setores da economia.

Tabela 3 - Geração da produção no Rio Grande do Norte

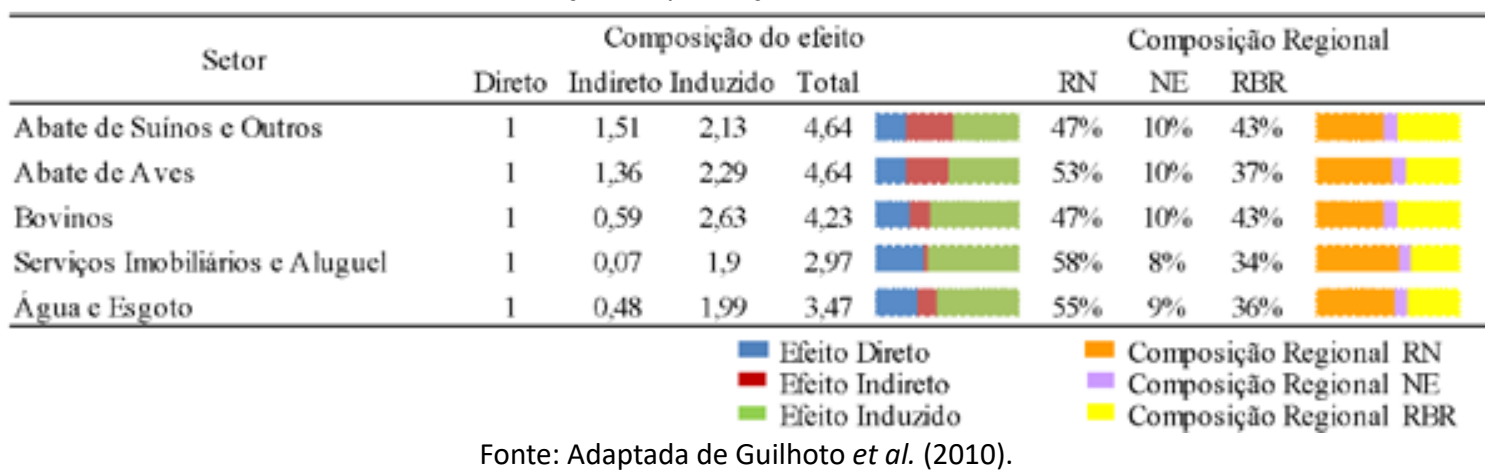

Esse aumento de um milhão na atividade bovina desencadeia um crescimento de 4,23 milhões da produção geral do sistema. Deste, $46 \%$ da criação bovina é destinada ao próprio Estado, $10 \%$ aos Estados do Nordeste e os $43 \%$ ao restante do país.

Dessa forma, observa-se que a criação de bovinos causa importante geração de produção, principalmente de forma induzida, em diversos segmentos, o que contribui para um meIhor fluxo da economia. Nesse sentido, Coutinho et al. (2019) comprovaram que as atividades da base pecuária criaram empregos e massa salarial de forma crescente, contribuindo para a dinamização das cidades, além de serem geradoras de insumos para outros setores, constituindo-se peças-chave na engrenagem da construção do desenvolvimento regional em Mato Grosso do Sul.

Na perspectiva do incremento da produção, enumera-se a produção de esterco pela pecuária, que representa uma alternativa importante para reduzir o uso de fertilizantes químicos 
e para diminuir o esgotamento do solo (FAERN, 2018). Nesse panorama, aponta-se o reaproveitamento do soro, resultante do processamento do leite, que, em decorrência da sua qualidade nutricional, pode ser utilizado na geração de produtos derivados, como ricotas e bebidas lácteas e na utilização na alimentação de outras espécies, como na de suínos. É nesse sentido que a Faern (2018) indica a suinocultura como atividade complementar em estágios da cadeia produtiva do leite, representando uma oportunidade, na medida em que o aproveitamento residual do soro na alimentação animal reduz significativamente os custos com as rações. Denota-se que produtores familiares rurais que realizam a integração dessas atividades encontram alternativas para complementar a renda.

A geração de produção no Estado do Rio Grande do Norte apresenta expressividade também nos setores voltados para o ramo alimentício, principalmente naqueles relacionados com os produtos de origem animal, como o abate de aves, suínos e, ainda, de bovinos, conforme mostrado na Tabela 3. Logo, o abate de suínos e outros animais possui um efeito total de geração de produção no valor de 4,64 milhões totais que são obtidos a partir de um incentivo que proporciona o aumento indireto de 1,51 milhões de reais na economia naquelas atividades de apoio, como é o exemplo da fabricação de embalagens e dos equipamentos necessários e do aumento da criação de animais para maior fornecimento dessa indústria.

No que se refere ao abate de suínos e outros, há um incremento na geração de produção induzida de 2,13 milhões de reais em virtude do aumento da renda das famílias, empregados, indústrias e governos, que demandam maiores quantidades de produtos e/ou serviços em outros setores. Desses efeitos econômicos, $47 \%$ são distribuídos pelo próprio Estado do RN, $10 \%$ nos demais Estados do Nordeste e $43 \%$ destinam-se ao restante do país. Nessa linha industrial de alimentos de origem animal, o abate de aves também produz um efeito gerador de produção total de 4,64 milhões de reais.

Os serviços imobiliários e aluguéis, no RN, apresentam-se com menor expressividade para a geração de valor agregado a produção. Os números revelam que são inseridos apenas 70 mil reais, quando investido um milhão, na produção indiretamente ligada a esse setor. Já em termos de indução em outros setores, este segmento é capaz de gerar 1,90 milhão de reais.

O segmento do saneamento, envolvendo água e esgoto, igualmente possui pequenas proporções quando comparado aos demais insumos-produtos para a geração de produção. De forma geral, é capaz de incrementar 3,47 milhões na economia das atividades indiretamente relacionadas.

Reitera-se que, normalmente, a geração de efeitos na produção é maior indiretamente para os setores manufaturados, que demandam maior diversificação de insumos em sua produção, e são mais propícios para a geração de produção induzida em razão do valor agregado à cadeia produtiva, pois são revertidos em compras ou vendas em demais setores econômicos (GUILHOTO et al., 2010).

\section{CONSIDERAÇÕES FINAIS}

A pecuária, de fato, é uma atividade que tem demonstrado relevância para o desenvolvimento de diversos municípios do Estado do Rio Grande do Norte. Percebeu-se, com base na análise da matriz insumo-produto, que este setor é responsável por considerável geração de 
emprego e possui potencial aumento da empregabilidade, notadamente de forma indireta e induzida, em outros setores econômicos, que dependem do fornecimento de leite e carnes.

Em relação ao desenvolvimento regional, a pecuária bovina tem impacto na diversidade produtiva de uma região, o que contribui para a redução da desigualdade econômico-social, conforme já comprovado em trabalhos científicos, como os de Griebeler et al. (2019) e Silveira et al. (2020). É ampla a diversificação dos produtos a partir da criação bovina que abrange a carne e a produção do leite e seus derivados, como o queijo de coalho e o de manteiga, a coalhada e a manteiga da terra. Há, ainda, o reaproveitamento do soro, resultante do processamento do leite, para a produção de ricotas e bebidas lácteas e, também, em razão de sua qualidade alimentar, para a utilização na alimentação de suínos, o que revela uma fonte complementar de renda.

Observou-se, da mesma forma, que a prestação de serviços no segmento da pecuária bovina, com produtos como vacinas, medicamentos e rações para os animais são ofertados da cidade para a zona rural. Sendo assim, é formada toda uma rede de comercialização e distribuição para adquirir os insumos e para fornecer o produto final, transporte de leite e seus derivados para o segmento de varejo.

Não se pode deixar de mencionar, no entanto, aspectos negativos associados à atividade da pecuária bovina: agressão ao meio ambiente, concentração de terras, baixa remuneração do setor e precarização das condições de trabalho, além da carência de acesso à tecnologias que aperfeiçoem a estrutura produtiva, aliada à insuficiência de capacitação profissional nas atividades do segmento (FAERN, 2018).

Por isso, para o progresso da pecuária revela-se viável que o Estado implemente políticas públicas que abranjam desde o estabelecimento de subsídios, de financiamentos, de gestão de distribuição dos recursos hídricos, de intensificação de programas institucionais de absorção dos produtos provenientes da pecuária até a qualificação técnica e investimentos em tecnologia, contribuindo para o melhor aproveitamento do solo e demais recursos naturais distribuídos no território.

A pecuária, portanto, é uma atividade que fornece meios bastante consistentes para consolidar o desenvolvimento da economia de uma região. Destarte, não se pode também desconsiderar a importância estratégica do setor e dos segmentos correlatos para contribuir com o processo de redução da exclusão socioeconômica.

Desse modo, o estudo sobre a pecuária constitui-se em uma ferramenta útil para a avaliação da necessidade e eficácia das políticas públicas para a geração de emprego e renda. Nessa perspectiva, percebe-se a importância de se ter uma política integrada que envolva as diversas atividades da pecuária e que abranja diferentes fatores intervenientes, tais como a gestão de recursos hídricos, acesso à água e o cuidado com meio ambiente.

O desenvolvimento desta pesquisa assegura a relevância que o Modelo Insumo-Produto proporciona aos planejamentos estratégicos para o bem-estar econômico e social de uma Região analisada. Dessa forma, a estabilidade Matemática e Computacional desse modelo assevera sua consistência para estudar as implicações econômico-sociais de um segmento na região, como foi o caso deste estudo, sobre a pecuária pautada na criação de bovinos no Estado do Rio Grande do Norte, que revelou maior geração de produção, de salários e de empregos, de forma a contribuir para o bem-estar social. 
Sugerem-se estudos que aprofundem a pesquisa sobre os aspectos econômicos das outras espécies abrangidas pela pecuária, tais como ovinos, caprinos e suínos, assim como recomendam-se análises das atividades diretamente relacionadas com a pecuária, como a agricultura e a agroindústria.

\section{REFERÊNCIAS}

BANCO CENTRAL DO BRASIL. Promove ajustes nas condições básicas do Crédito Rural. Resolução n. 3.599, de 29 de agosto de 2008. Disponível em: https://www.bcb.gov.br/pre/normativos/busca/downloadNormativo.asp?arquivo=/Lists/Normativos/Attachments/47839/Res_3599_v1_O.pdf. Acesso em: 30 jun. 2020.

BANCO CENTRAL DO BRASIL. Dispõe sobre ajustes nas normas do Programa Nacional de Fortalecimento da Agricultura Familiar (Pronaf), de que trata o Capítulo 10 do Manual de Crédito Rural (MCR), para aplicação a partir do ano agrícola 2014/2015. Resolução n. 4.339, de 20 de junho de 2014. Disponível em: https://www.bcb.gov.br/pre/normativos/busca/downloadNormativo.asp?arquivo=/Lists/Normativos/Attachments/48709/Res_4339_v1_O.pdf. Acesso em: 30 jun. 2020.

BELTRAME, G.; PEREIRA, B. A. D. Impactos socioeconômicos ocasionados pelo Pronaf para o desenvolvimento da agricultura familiar. Desenvolvimento em Questão, ljuí: Editora Unijuí, RS, v. 15, n. 38, p. 87-107, 24 mar. 2017. DOI: http://dx.doi.org/10.21527/2237-6453.2017.38.87-107. Disponível em: https://www. revistas.unijui.edu.br/index.php/desenvolvimentoemquestao/index. Acesso em: 5 fev. 2021.

BRASIL. Constituição da República Federativa do Brasil de 1988. Disponível em: http://www.planalto.gov. br/ccivil_03/constituicao/ConstituicaoCompilado.htm. Acesso em: 15 abr. 2020.

BRASIL. Ministério da Economia. Produtividade e comércio exterior. Empresas brasileiras exportadoras e importadoras. Brasília, DF, 2020. Disponível em: https://www.gov.br/produtividade-e-comercio-exterior/ pt-br/assuntos/comercio-exterior/estatisticas-de-comercio-exterior/empresas-brasileiras-exportadoras-e-importadoras/copy_of_empresas-brasileiras-exportadoras-e-importadoras. Acesso em: 3 jul. 2020.

CANO, W. Introdução à economia: uma abordagem crítica. São Paulo: Unesp, 1998. 264 p.

CARDOSO, B. F.; OLIVEIRA, T. J. A. de; SILVA, M. A. da R. Eletrificação rural e desenvolvimento local: uma análise do programa luz para todos. Desenvolvimento em Questão, Unijuí, v. 22, n. 11, p. 117-138, 2013. Quadrimestral. Disponível em: https://www.revistas.unijui.edu.br/index.php/desenvolvimentoemquestao/about. Acesso em: 29 jun. 2020.

COSTA, J. C. B. da. Programa Leite Potiguar: uma avaliação das ações no município de Currais Novos/RN. 2017. Trabalho de Conclusão de Curso (Curso de Administração) - Universidade Federal do Rio Grande do Norte, Currais Novos, RN, 2017.

COUTINHO, M.; BITENCOURT, M.; FIGUEIREDO-NETO, L.; FIGUEIREDO, A. A contribuição das atividades de base agropecuária na geração de emprego nos municípios de Mato Grosso do Sul (Brasil). Revista Latinoamericana de Estudios Urbano Regionales - Eure, Santiago, Chile, v. 45, n. 135, p. 223-244, 2019. Disponível em: https://www.eure.cl/index.php/eure. Acesso em: 10 jul. 2020.

DIAS, T. F.; NUNES, E. M.; TORRES, F. de L.; TORRES, A. C. M. O Programa de Aquisição de Alimentos da Agricultura Familiar (PAA) como estratégia de inserção socioeconômica: o caso do Território da Cidadania Sertão do Apodi (RN). Revista Brasileira de Gestão e Desenvolvimento Regional, Taubaté, SP, v. 9, n. 3, p. 100-129, 2013. Disponível em: https://www.rbgdr.net/revista/index.php/rbgdr/article/view/1127. Acesso em: 10 jun. 2020.

DINIZ, C. C. Celso Furtado e o desenvolvimento regional. Nova Economia, Belo Horizonte, MG, 2009. Disponível em: https://revistas.face.ufmg.br/index.php/novaeconomia/index. Acesso em: 25 fev. 2021.

DINIZ, C. C.; GONÇALVES, E. Economia do conhecimento e desenvolvimento regional. In: DINIZ, C. C.; LEMOS, M. B. Economia e território. Belo Horizonte: Editora da UFMG, 2005.

DINIZ, C. C.; SANTOS, F.; CROCCO, M. Conhecimento, inovação e desenvolvimento regional/local. In: DINIZ, C. C.; CROCCO, M. Economia regional e urbana: contribuições teóricas recentes. Belo Horizonte: Editora da UFMG, 2006.

EURICH, J.; WEIRICH NETO, P. H.; ROCHA, C. H. Pecuária leiteira em uma colônia de agricultores familiares no município de Palmeira, Paraná. Revista Ceres, Viçosa, MG: Fap Unifesp (Scielo), v. 63, n. 4, p. 454-460, 2016. DOI: http://dx.doi.org/10.1590/0034-737x201663040004 
FAERN. Federação da Agricultura, Pecuária e Pesca do Rio Grande do Norte. Propostas para a Agropecuária Potiguar - 2019-2022. Natal, RN, 2018. Disponível em: https://www.senarrn.com.br/. Acesso em: 10 jun. 2020.

FILGUEIRA, J. M.; PEREIRA JÚNIOR, A. O.; BARBOSA DE ARAÚJO, R. S.; SILVA, N. F. Economic and Social Impacts of the Oil Industry on the Brazilian Onshore. Energies, v. 13, n. 1922, 2020. Disponível em: https:// www.mdpi.com/1996-1073/13/8/1922.

FIRME, V. de A. C. As relações setoriais entre Minas Gerais, restante do Brasil e seus 5 principais parceiros econômicos: uma abordagem de insumo-produto. Revista Brasileira de Economia. Rio de Janeiro, RJ, v. 71, n. 4, 2017. DOI: 10.5935/0034-7140.20170020

FURTADO, C. Formação econômica do Brasil. São Paulo: Nacional, 1964.

FURTADO, C. Intra-country discontinuities: Towards a theory of spatial structures. Social Science Information, v. 6, p. 7-14, 1967.

GUILHOTO, J. J. M.; AZZONI, C. R.; ICHIHARA, S. M.; KADOTA, D. K.; HADDAD, E. A. Matriz de insumo-produto do Nordeste e Estados: metodologia e resultados. SSRN Electronic Journal, dez. 2010. DOI: http:// dx.doi.org/10.2139/ssrn.1853629

GRIEBELER, M. P. D.; MATTE JUNIOR, A. A.; BERTI, F.; ALVES, D. de. Atividades econômicas, geração de emprego e análise do potencial de desenvolvimento do município de Campo Bom/RS. Desenvolvimento em Questão, ljuí, RS: Editora Unijuí, v. 17, n. 49, p. 276-290, 17 out. 2019. DOI: http://dx.doi. org/10.21527/2237-6453.2019.49.276-290

HENRIQUE, F.; FILHO, U. A. S. F.; SILVA, J. V. B. da; BRENE, P. R. A. Estrutura produtiva do Estado do Paraná e identificação de setores-chave para o desenvolvimento. Revista Brasileira de Gestão e Desenvolvimento Regional, Taubaté, SP, v. 15, n. 7, Edição Especial, p. 215-225, dez. 2019. Disponível em: https://www.rbgdr.net/revista/index.php/rbgdr/article/view/5270. Acesso em: 7 jul. 2020.

ISARD, W. Inter-regional and regional input-output analysis: a model of a space-economy. Review of Economics and Statistics, n. 33, p. 319-328, 1951.

LEONTIEF, W. W. Structure of american economy. 2. ed. New York: Oxford University Press, 1953.

LEONTIEF, W. A economia do insumo-produto. São Paulo: Abril Cultural, 1983. 225 p. (Série "os economistas").

MARCONI, M. de A.; LAKATOS, E. M. Fundamentos de metodologia científica. 6. ed. São Paulo, Atlas 2003. $312 \mathrm{p}$.

MOTA, M. K. F. Importância social e econômica do setor de energia elétrica no Nordeste e no Rio Grande do Norte: uma análise de insumo-produto. 2012. 91 f. Trabalho de Conclusão de Curso (Tecnólogo em Comércio Exterior) - Instituto Federal de Educação, Ciência e Tecnologia do Rio Grande do Norte (IFRN), Natal, RN, 2012.

MOTA, M. K. F.; BARBOSA, R. S.; FILGUEIRA, J. M. Desenvolvimento regional baseado na educação: uma análise insumo-produto no Estado do Rio Grande do Norte - Brasil. Revista Brasileira de Gestão e Desenvolvimento Regional, Taubaté, SP, v. 11, n. 1. ISSN 1809-239X., 2015. Disponível em: https://www.rbgdr. net/revista/index.php/rbgdr/article/view/1615. Acesso em: 2 abr. 2020.

MOREIRA, G. R. C. Políticas sociais, desigualdades pessoais e regionais da renda no Brasil: uma análise de insumo-produto. 2007. 95 f. Dissertação (Mestrado) - Universidade de São Paulo Escola Superior de Agricultura "Luiz de Queiroz", Piracicaba, 2007.

NEREUS. Núcleo de Economia Regional e Urbana da Universidade de São Paulo. Disponível em: http:// www.usp.br/nereus/?p=2099. Acesso em: 17 abr. 2020.

PERROUX, F. A economia do século XX. Porto: Herder, 1967.

SANÉN, N. E. A.; GAMBOA, J. M. S. A Methodological Proposal for the Construction of a Regional Input-Output Matrix Using a Bottom-up Approach and Its Statistical Assessment. Investigación Económica, v. 75, n. 298, out. 2016, p. 3-56. DOI:10.1016/j.inveco.2016.11.001

SILVEIRA, R. L. L. da; SILVEIRA, D. C. da; BRANDT, G. B.; ZANCHI, V.; OLIVEIRA, V. G. de. Observando a dinâmica territorial do emprego e do deslocamento para trabalho na Região do Vale do Rio Pardo-RS. Desenvolvimento em Questão, Ijuí, RS: Editora Unijuí, v. 18, n. 51, p. 186-209, 24 abr. 2020. DOI: http://dx.doi. org/10.21527/2237-6453.2020.51.186-209

SOUZA, E. M.; AQUINO, J. R. A grande seca e seus efeitos na produção agropecuária do Rio Grande do Norte: 2012-2016. Revista GeoNordeste. São Cristóvão, SE, ano XXIX, n. 2, p. 174-195, jul./dez. 2018. 